\title{
The Presentation of Self in a Virtual but Work-related Environment From Protagonists to Fools
}

\author{
Emmanuelle Vaast \\ Long Island University, School of Business, 1 University Plaza- \\ H700, Brooklyn, NY 11201, USA. \\ emmanuelle.vaast@liu.edu
}

\begin{abstract}
More and more people take part in virtual environments in which they present a "virtual self"- an online profile that indicates key information about them to other participants and viewers. This research investigates how people present themselves in the virtual yet work-related environments of occupational online forums. To do so, the research analyzes the profiles of more than 300 registered users of an online forum dedicated to issues of interest to bankers. These profiles are interpreted in relation to Goffman's (1959) seminal ideas of mystification (allowed by the separation between backstage and public action) and presentation of self and of Turkle's (1995) ideas of multiple, interrelated, online and offline selves. This research builds a grounded categorization of profiles. The four categories of profiles that emerged from the data correspond to clearly distinct ways participants in the online forums present themselves. Over time, two categories have become dominant while another has dwindled. This research holds implications for the understanding of the presentation of self in virtual but work-related environments. It shows how participants in online forums build their virtual self by playing with the mystification inherent of the virtual environment. It also shows an interplay between the virtual and the offline when some participants "de-mystify" their profile. Finally, the increasing prevalence of two categories of profiles suggests that, over time, social norms of presentation of self emerge and condition socially accepted virtual selves in occupational online forums.
\end{abstract}




\section{Introduction}

The increasing ubiquity of electronic communications has changed the way people present themselves by providing greater freedom from the constraints of direct interactions, physical appearance, and disabilities [1-4]. The history of the Internet is full of stories of people who created an online persona that fooled others [5-6]. "Lonelygirl15" on Youtube is one such recent example of how people can manipulate the self they present in a virtual environment ${ }^{1}$.

More generally, the virtuality of electronic communications makes it possible for people to control how they present themselves in ways that they deem favorable, as has been shown in the context of online dating and personal web pages [7-8]. This greater ability to control one's presence in a virtual environment than in regular "offline" contexts has become even more widespread as more and more people have become part of various virtual environments, either to play video games, discuss hobbies or news-related topic, find support for difficult offline situations, or ask, find, and exchange information related to one's job [9].

With regard to online forums in which people can exchange occupational information, the literature has already noted their learning potential [10], and it has discussed the motivation to actively participate versus merely lurking in these forums [11-15]. People usually become active users in these forums by filling out a profile that allows them to post questions and to get answers on issues related to their occupation. Despite the popularity of these forums and the fact that they attract many participants from various occupational fields, so far, the literature has not yet investigated the ways in which people present themselves in these forums. Yet, to convey an impression on the audience of the forums, one can expect that participants craft their online presence in a certain way, taking advantage of the greater freedom allowed by the electronic media. For instance, Butler et al. [15] suggested that certain (but not all) members of online forums take on authority roles without becoming official administrators of the forums. Also, McLure, Wasko, and Faraj [11] showed that active participants want to improve their reputation. It is possible that such members of online forums present themselves in ways that are designed to convey authority and to improve reputation.

This research investigates the ways in which people build their presence in the virtual environment of occupational online forums and, more precisely, explores how participants in occupational online forums present themselves when adopting an online profile.

The paper is organized as follows. It first presents Goffman's [16] conceptualization of presentation of self and explores how this conceptualization can be updated to fit virtual environments. Then, the investigated forum and interpretive research methods are presented to introduce the grounded analysis of more than 300 online profiles of users of the "Bankers On Line" (BOL) forum, an online forum dedicated to banking issues. The discussion section interprets how the different

${ }^{1} \mathrm{http}: / /$ www.youtube.com/profile?user=lonelygirll 5 
profiles in the samples express various ways of building a virtual self. It analyzes how these profiles may be related to offline situations and shows how the evolution over time of these profiles indicates the emergence of social norms of presentation of self. The conclusion section summarizes the research, presents its limitations as well as its main conceptual and practical implications.

\section{Presenting Oneself in a Virtual Environment}

\subsection{Goffman and the Encounters of Everyday Life}

Goffman was fascinated by the micro-sociological encounters that constitute social life. In particular, he developed a dramaturgical perspective in which people involved in interactions produce performances that aim at producing a certain impression on the audience [16]. In this perspective, performances and impressions are partly shaped by the social environment and by the audience's interpretation. An important dimension of the performance is its "front," that is, "that part of the individual's performance which regularly functions in a general and fixed fashion to define the situation for those who observe the performance." [16, p. 22]. Through his analysis, Goffman explored the relations between individual performances and social identity and contended that some fronts become prevalent and socially accepted by the audience and the performers.

\subsection{The Presentation of Self in Virtual Environments}

Goffman's seminal analysis solely concerned situations in which people are "in one another's immediate physical presence" [16, p.15], which does not fare well with a virtual environment. Interestingly, however, Goffman noted in [17, p. 2]:

Social interaction can be identified narrowly as that which uniquely transpires in social situations, that is, environments in which two or more individuals are physically in one another's presence. (Presumably, the telephone and the mails provide reduced versions of the primordial real thing).

Virtual environments, in which interactions take place electronically, may also be viewed as other "reduced versions" of the "primordial real thing" with specific characteristics that affect the front that people can adopt. In this regard, electronic media arguably provide more limited opportunities than face-to-face interactions to present a sophisticated front, since people cannot rely on the rich palette of cues conveyed by co-presence $[5 ; 18]$. The difficulty to rely solely on words to convey complex messages and the occasional e-"flaming" that results in miscommunications and confusions are illustrations of the less sophisticated front that people present in virtual environments [19]. 


\subsection{Mystification and Virtual Interactions}

Yet, electronic communications allow for a greater "mystification," in Goffman's terms, that is, for a greater distance between performers and the audience, keeping the audience at awe. The audience's lack of access to the offline backstage of the performance creates such potential for greater mystification. Participants in virtual environments can therefore easily hide aspects of their offline persona they do not want known to others, while emphasizing other aspects they deem presentable. Such presentation of self online may also disinhibit from offline constraints $[6 ; 20-21]$. Turkle [6], in particular, showed how MUD users are able to present multiple fronts simultaneously in various virtual environments, and that, very often, these virtual fronts help MUD players cope with their offline situations.

There lays a question, though. So far, the literature on the presentation of self in virtual environments has been mostly dedicated to the investigation of individuals' or companies' web pages and blogs [22-24]. It has showed how people present a certain image of themselves online and has investigated the main characteristics of these images [8]. It has proposed that, online, people follow a strategy of ingratiation, through which they seek to be liked by others, or of competence, wishing to be perceived as skilled and competent [25-26]. Hence, these studies have corroborated the idea that people try to present themselves in an idealized way [27]. However, they have not yet investigated the social nature of mystification and idealization. Essential to Goffman's conceptualization is that, through mystification, people aim at producing an impression that is socially sanctioned, and that the personal front represents norms and values that are consistent with the social groups or communities with which people identify $[16$, pp. 67-70; 28]. Idealization and mystification are thus not mere strategies of the individual. Rather, they are social in nature; they position people in their social environment.

The literature on the presentation of self in virtual environments has not yet much investigated this social dimension. The data collected for this research thus aimed at exploring the presentation of self in an occupational online forum and, possibly, at identifying emergent social norms of presentation of self in a virtual and workrelated environment.

\section{Methods}

\subsection{Research Setting: Bankers On Line Forum}

An online forum dedicated to issues of interest to bankers constitutes the setting of this research. This forum is publicly available from Bankers On Line (BOL) ${ }^{2}$, a website dedicated to all banking issues that includes news, legal information, training opportunities, blogs, and a forum. Most contents of the BOL website are publicly available. The BOL website was selected for two reasons. First, bankers are not

${ }^{2}$ www.bankersonline.com 
known for being especially computer savvy or extremely willing to adopt innovative behaviors with regard to IT (as contrasted with, say, computer programmers or analysts). Focusing the investigations on the presentation of self of members of an occupation that cannot be considered among the "early adopters" of IT could provide an idea of how "mainstream" impression management in occupational yet virtual environments had become. Second, the BOL website is well-known in the banking industry and various members of the occupation acknowledged (independently from this research) their repeated use of the website and mentioned the popularity of the website among their colleagues.

This research analyzes profiles filled by registered users of the BOL forum. Overall there are more than 12,000 registered users (Fall 2006). Registration is free and open to anyone from the banking and the non-banking industries. Registered users can browse the threads but cannot participate in the discussions. It is noteworthy that, until after data were collected, anyone (registered or non-registered users) could freely browse the profiles of registered users. Registered users (henceforward called users) can browse, ask, and answer any question on any BOL forum (about 20 threads in Fall 2006, dedicated to issues ranging from compliance to state specific issues and from chat to security or human resources, see url: http://www.bankersonline.com/ubbthreads/ubbthreads.php/Cat/0).

Participants' profiles consist of various items that users may or may not fill: user id (only mandatory field), e-mail, member number (automatically attributed depending on when the user registered), homepage, occupation, hobbies, location, birthday, bio, and date of registration. The BOL website also automatically gives users' a "title" (according to the number of posts), and publishes their total posts. Figure 1 provides an example of such a profile.

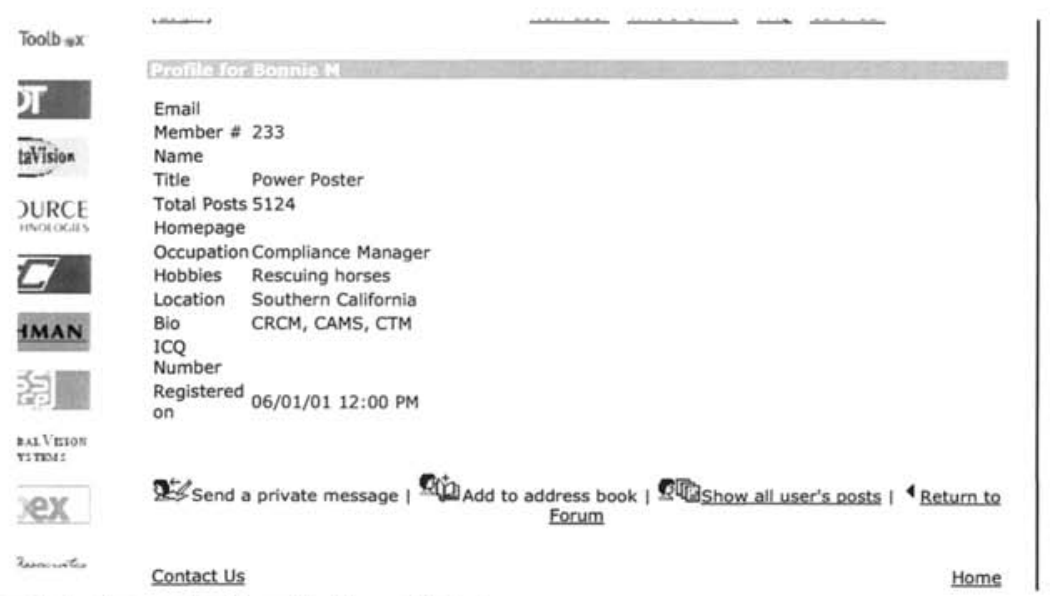

Figure 1. Example of profile from BOL forum. 


\subsection{Data Collection and Analysis}

Data collection took place in two stages, in January-February 2006 and in August-September 2006. During the first stage, a sample of profiles from three major discussion threads was collected: the "Ask a banker" thread, in which non-bankers ask questions about any issue they may have with banking ("What is a good credit score?"); the "Compliance" thread which deals with compliance, a central issue for bankers ("How to document a lending application when the applicant is doing a joint application with another institution?"); and the "Chat" thread, in which performers freely discuss non-banking related issues (dating troubles). 50 users from these threads were randomly selected. Due to cross-listings-users can participate in any discussion from the BOL forum - the first sample contained 129 users.

These 129 profiles were analyzed through descriptive quantitative and qualitative analysis. The descriptive quantitative analysis (number of items in the profile filled by participants) gave a sense of how different participants in the forums filled out their profile, and helped initiate comparisons among profiles. In particular, the distribution of number and types of categories in the profiles filled, as well as the date of registration were analyzed. The qualitative analysis helped interpret individual profiles and identify patterns in presentation of self. It relied on wellestablished qualitative approaches for data reduction and analysis [29-30] including the Straussian version of grounded theorizing [31-32] that allows for a continuous dialog between previously established conceptualizations and inductive observations. In particular, I developed a thematic coding of different items of the profile (user id, hobbies) that followed the guidelines of grounded theorizing (open, axial, selective coding of profiles).

The results of the exploratory quantitative and qualitative data analysis were put together to establish a categorization of profiles. The four emerging categories were labeled as four types of characters in a play, in a way that followed Goffman's [16] analogy: protagonists, deuteragonists, tritagonists, and fools [33-34]. The categorization aimed at making sense of the variety of profiles while possibly identifying similar ways of presenting oneself in the BOL forum. Forum users were assigned to different categories by following a principle of internal homogeneity and external heterogeneity [35]. The attributes concerned the main categories of the profile (i.e. user id, picture, e-mail, occupation, hobbies, bio) and emerged from the thematic coding.

In order to test the reliability of the analysis and the categorization beyond the three aforementioned threads, a second sample of 180 profiles of users was randomly selected from all threads of the forums ( 10 users per thread). These 180 profiles were analyzed and categorized. Results were highly comparable, especially in terms of proportion of users in each of the four categories. To test the reliability of the typology, a second, independent, coder was asked to double code all profiles of the two samples (total: 309 users). The inter-coder agreement rate for the two combined samples was of $88.6 \%$ and deemed acceptable.

Consistent with Goffman's symbolic interactionist perspective [36], the epistemological stance of this research is interpretive and assumes that "our 
knowledge of reality is gained only through social constructions such as a language, consciousness, shared meanings, documents, tools, and other artifacts" [37, p. 69]. Because data were entirely secondary, Klein and Myers' [37] guidelines for the conduct of field studies did not apply readily. However, I strove to respect the principles of hermeneutic interpretive research presented by Klein and Myers. In particular, Lee's [38] joint investigation of individual e-mails and overall context was an inspiration to take in consideration the principles of hermeneutic circle and contextualization. In the present research, individual profiles were constantly related to one another to make sense of the differences and similarities among them, and to interpret the overall meanings of the profiles. Also, as this research relied on secondary data, there was no direct interaction with users. In order to respect the principles of suspicion and multiple interpretations, I relied on double coding of the profiles. Finally, the principle of abstraction and generalization was respected by constantly confronting my interpretations with existing conceptualizations, in particular with Goffman's [16] presentation of self, Turkle's [6] multiple online identities and Donath's [18] mystification in online contexts.

\section{Interpreting BOL User Profiles}

\subsection{User Id and Number of Filled Fields}

The user id was the only required field of the registration form. More than $70 \%$ of users from the samples (222/309) chose a user id that seemed significantly different from their "real" offline name. The samples showed diversity in these ids, but a few patterns appeared. Among the main sources of inspiration were the banking world: (sometimes with a twist of humor: "Blue Banker," "Compliance 101"), hobbies ("Redsoxfan" or "Georgia Golfer"), pop culture ("Princess Leia"), and even values or ideas ("Bliss"). Some user ids seemed to reflect the disinhibiting effect of virtuality noted by the literature ("Wacokid" or "Wild turkey"). Others seemed to reveal a desire to remain anonymous ("Random name" or "barely there"). In contrast, a third of users $(87 / 309)$ chose user ids that seemed credibly related to their offline id (user id: "Len S"; name: Len Suzio, or "Don Narup").

In addition to this required field, users could fill out any other fields: image, email, name, birthday, homepage, occupation, hobbies, location, and bio. Users in the samples filled out some of the 0 non-required fields $(\min =0, \max =9$, average $=$ 3.10 , standard deviation $=2.05$ ). Table 1 presents the distribution of number of filled fields in the combined samples. 
Table 1: Number of non-required categories filled in online profiles

\begin{tabular}{|c|c|}
\hline \# of filled fields & \# of profiles \\
\hline 0 to 2 & 121 \\
\hline 3 to 5 & 118 \\
\hline 6 to 8 & 70 \\
\hline Total & 309 \\
\hline
\end{tabular}

Among the profiles with few filled fields ( 0 to 2$)$, the fields that were most often filled were the birthday, location, or the occupation. Among profiles with an average number of filled fields ( 3 to 5), the fields usually filled were: the birthday, picture, occupation, hobbies, location, and / or bio. The fields that were not usually filled were the e-mail, name, and homepage. Among the profiles with many filled fields ( 6 to 8 ), the categories that were least filled were the birthday and the picture. The categories that were the most filled were the ones related to the banking world (occupation, bio).

Regarding how the categories were filled, again, several patterns appeared. Among the users who filled out very few categories in their profiles, the categories that were filled were so with few words and with a high degree of generality (occupation: "banker" or "marketing dude"). Among the profiles with an average number of filled fields, there seemed to be two main groups of profiles in the samples. Most of these users filled fields out with information that credibly seemed to come from their offline situation (occupation: "V.P. compliance" or bio: "17 years of risk management experience in compliance and internal audit. CRCM and CFSA"). Occasionally, fields were filled with distance and humor (bio: "Being a good worker is 3\% talent, $97 \%$ not being distracted by the Internet"). In profiles where a large number of fields were filled, certain fields (in particular, the occupation and the bio) were filled in a very specific and detailed way (occupation: "CRA Officer \& Community Relations Coordinator" or bio: "OCC Regulated $\$ 370$ million in assets, Jack Henry Silverlake bank, ABA Compliance School Graduate, OBA Banking School Graduate").

\subsection{Specific Fields in the Profiles}

With regard to the fields of occupation and bio, 191 profiles of the sample provided the user's occupation, 69 of them presented a bio, and 58 presented both their occupation and a bio.

Among the profiles that provided an occupation and/or a bio, despite the varying degrees of detail, there was a relative homogeny in the information presented. Occupation and bio often mentioned the job title currently and previously occupied, but never the name of the company, even though no explicit rule forbade it in the BOL forum. In the same vein, profiles usually included technical and professional certifications but, save exceptions, did not mention degrees or institutions. The occupation field seemed to hint at how users wanted to be perceived (a banker who works in compliance, v.p., loan assistant) as well as what they did not want to be 
associated with ("NotALawyer"). Overall, the profile also hinted at how users perceived the banking community. In this matter, some users expressed distance visà-vis the banking world, very often through humor (occupation: "Slave, oh, I mean, loan assistant" hobby: "anything non-banking", or bio: "I did not want to grow up to be in compliance, I wanted to be a rock star").

Ninety-four profiles mentioned hobbies. The hobbies presented fell into only a few categories: indoor activities (reading, scrap booking, cooking), outdoor activities (fishing, sailing, hiking), and sports (golf, volleyball). The proper character of these hobbies was noteworthy. There was no mention of "TV," "gambling," "smoking," "bar hoping," or any non-socially sanctioned hobby. Just as they would probably not have claimed publicly in their workplace that they love to gamble, BOL users avoided mentioning any hobby that was not socially sanctioned offline. What is more, in some profiles, the presentation of hobbies seemed to reinforce the impression of professionalism or of social status. Golfing appeared very often in the hobbies, which reminded of the way in which, in (offline) work environments, mentioning that one is a golfer contributes to establish one's status. In the same way, the family and, especially, the children or grand-children, were often mentioned in the hobbies category ("reading/playing with my son" or "Playing with my step daughter. Isn't being a parent the coolest thing?"). In the BOL profiles, the frequent mention of kids among the hobbies reminded of the picture of the kids that one finds on people's desk.

Regarding pictures, few were the profiles that presented pictures that credibly looked like pictures of the "real" users (less than 20 in the samples). Most pictures were related to the user id, to a landscape (horses running), or pop culture (Tinkerbell, The Matrix, Superman logo). Many pictures were animated jpegs that presented little clips of action that usually bore no direct relationships with the banking occupation.

Table 2: Examples of profiles from each category

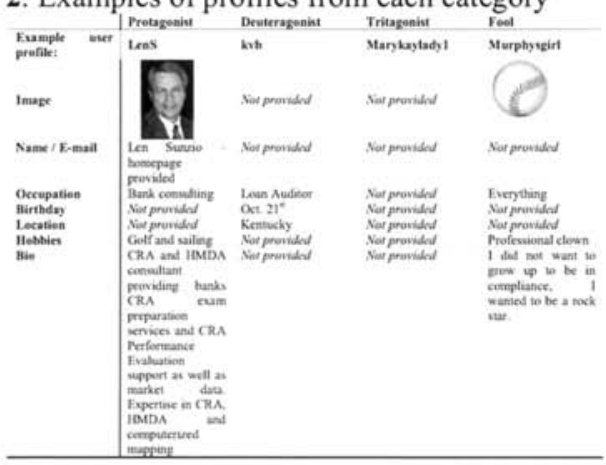

\subsection{Four Categories of Profiles, Like Characters in a Play}

Putting together the similarities and differences in users' profiles, four categories of profiles emerged. As noted supra, consistent with Goffman's dramaturgical 
analogy, these four categories were named after typical characters in a play [33]: Protagonist (the leading character); Deuteragonist (a secondary character); Tritagonist (a minor character whose specific background the audience is not made aware of), and; Fool (a humorous character). Table 2 illustrates each of these profiles with examples from the samples, and Table 3 presents the number and percentage of profiles from the two samples in each category.

Table 3: Number and percentage of profiles in each category of the samples

\begin{tabular}{|c|c|c|}
\hline Category of profiles & $\begin{array}{c}\text { Number in the } \\
\text { samples }\end{array}$ & $\%$ \\
\hline Protagonists & 54 & 17.48 \\
\hline Deuteragonists & 140 & 45.31 \\
\hline Tritagonists & 103 & 33.33 \\
\hline Fools & 12 & 3.88 \\
\hline Total & 309 & 100 \\
\hline
\end{tabular}

The "Protagonist" category represents the profiles where most fields were filled and where users seemed willing to provide information that could identify them in their "offline" world. In these profiles, users often adopted a user id that included their first and last name, and/or they provided their e-mail address or a link toward their website. Also, this category contrasted with the other ones in the sample by providing a relatively high degree of detail for fields related to the banking occupation (occupation, bio).

In contrast, within the "Deuteragonist" category, not so many fields were filled and profiles did not include information that could identify the user in his / her offline situation. Also, banking-related fields were not filled with much detail, but some information about the occupation and/or the bio, location, and hobbies was usually provided.

The "Tritagonist" category grouped together profiles in which very few fields were filled beyond the mandatory choice of userid. Profiles from this category provided very little information about the offline or even the online persona of users.

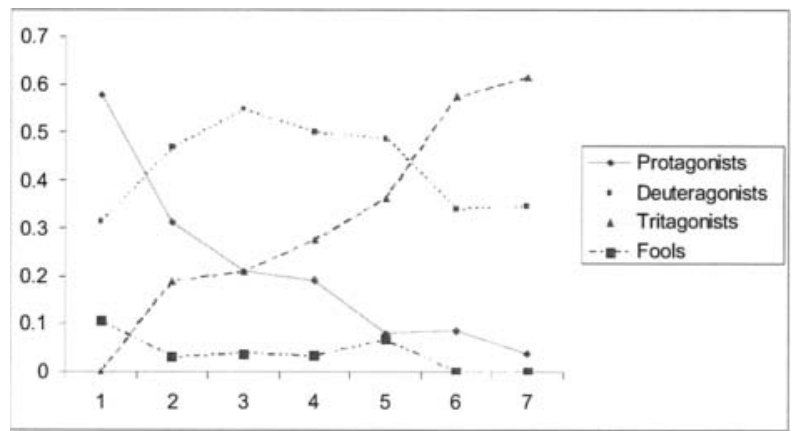

Figure 2. Proportion of new profiles in the BOL forum per category and per year 
Finally, the few profiles from the "Fool" category had more filled fields than the "Tritagonist" one. The playfulness and multiplicity of jokes or humor spikes inside the fields characterized this category of profiles.

Substantial differences appeared with regard to the year of registration of users of different categories of profiles. Figure 2 presents the proportion of new profiles from each category.

The "Fool" category was unusual but relatively stable over time. After 2001, the "Deuteragonist" category became the most frequent category. In contrast, the "Protagonist" category was much more frequent among the users who registered during the first years of the BOL forum. It became steadily less adopted as users registered in later years. The "Tritagonist" category followed a reverse evolution. It was adopted on average by between a sixth and about a quarter of the users who registered until 2003. After 2003, though, the proportion of new users who adopted a tritagonist profile increased dramatically and, since 2005, it has been the dominant category of adopted profiles among new users.

\section{Discussion}

\subsection{Playing with a Virtual Front}

Profiles can be interpreted as "fronts" (in Goffman's terminology) that users present in the virtual environment of the BOL forum. Users picked and chose different aspects of their personality and life offline to be presented in their profile. They also took advantage of the disinhibiting effects of electronic media. For instance, the pictures of the profiles were rarely directly related to the main official purpose of the BOL forum (discussing banking-related issues) and allowed BOL users to exert their freedom of choosing any front, freed from the constraints of wearing a suit and a tie in the day-to-day job.

These observations, which are consistent with the existing literature $[18,5]$, could lead to suggest that profiles were highly diverse. Yet, there was a limited diversity among them. This limited diversity was observed in the few markers of offline social identities that transpired in the BOL profiles, as well as in the expression of membership to the banking world.

First, a few markers, of offline social identities crossed over most of the profiles. In particular, gender and motherhood surfaced very often in the profiles (userid: "LadyJoey's mom" or hobby: "Mom to a 5-year-old"). Such observation was consistent with the existing literature on online behaviors that has suggested that gender differences are reproduced in virtual environments [39]. Beyond corroborating these existing insights, though, the BOL profiles also revealed the absence of other social markers of identity that are prevalent in offline environments (age, ethnicity). Also, while training and past experiences were often mentioned in the profiles, there was usually no detail about the certifying institution and the previous companies for which the user had worked. These observations support the idea that BOL users were playing with the aspects of their offline self they presented 
in the virtual environment of the BOL forum: they fine-tuned the degree of "mystification" of their online profile. These observations also suggest that social norms of what was to be presented in the profiles (and what was not to be presented) had emerged.

Second, most BOL forum users were brought together by the sharing of a common occupation. The profiles they adopted often explicitly expressed this workrelated bond. Many userids were related to banking ("Compliance man," "BankerBoy," or "Fraudpup"). The irony and distance that often accompanied these ids as well as other fields (job: "Slave, oh, I mean, loan assistant") was striking. It suggests an ambivalence of BOL users with regard to their identity and practices as bankers, ambivalence that is not uncommon with regard to occupational identities [40-41]. With their profiles, users distanced their virtual front from the image they had of their banking occupation while also re-affirming their membership to the occupation. Other aspects of their profiles seemed to reproduce in the virtual environment some prevalent social norms in the work context. In particular, many hobbies presented in the profiles are socially accepted and even considered as conveying social status in the workplace (golfing, sailing). The frequent occurrence of these hobbies in the profiles suggests that the online profiles reproduced in a virtual environment some of the (often tacit) social norms prevalent in the workplace on how to present one's self.

\subsection{Mystification and De-mystification in a Virtual Environment}

It has been suggested that mystification is more strongly established in virtual environments than in offline ones since the distance between the audience and the performance can easily be maintained [see supra and 18]. Yet, two categories of profiles of BOL users revealed unexpected insights with regard to mystification.

First, profiles in the "Protagonist" category provided a lot of information on the user's offline situation (full first name and last name, e-mail, website). In this virtual environment in which mystification was very easy to achieve, these users "demystified" their profile; that is, they limited the distance between the front they presented online and their offline situation, allowing the audience to reach them offline. Such "de-mystification" may have been used to build the credibility of one's online persona and to make others in the virtual environment trust the user. Demystifying an online profile may thus have been part of an impressions management tactic. In a virtual environment where anyone can be anything and anyone else, providing credible information about one's offline situation may be used to build a feeling of truthfulness with regard to the overall virtual persona, which may be especially valuable in work-related environments.

Second, the few profiles of the "Fool" category revealed an opposite tendency with regard to mystification. Most of the fields of the "Fool" profiles were filled with jokes and humor that made the profile seeming very far from what could be the offline professional persona of the BOL user. The "Fool" profiles thus seemed to push further the logic of mystification. The jokes and apparent significant distance 
between the online profile and the offline situation could be easily identified and contrasted with the majority of profiles in the BOL forum, which seems to indicate that some expectations with regard to what was to be presented in user profiles in the BOL forum had emerged.

\subsection{Front Selection and Emerging Social Norms of Presentation of Self}

In Goffman's [16] perspective, the samples' limited diversity of profiles is an indication of the social nature of the presentation of self. The emerging prevalence of two of these categories of profiles (the Deuteragonist and the Tritagonist ones, see figure 2) can thus be interpreted as a sign that the virtual environment of the BOL forum had become a virtual social entity whose participants respected emerging shared norms of presentation of self.

The evolution over time of new profiles in each category was thus consistent with Goffman's assertion that "fronts are selected, not created" [16, p. 28]. The prevalent categories of profiles changed over time, suggesting that the adoption of a new profile participated in the negotiation (reproduction and transformation) of the emerging social norms of presentation of self in the BOL forum. For instance, it is hardly surprising that the "Protagonist" category was the dominant one at first. In the absence of established references in the BOL forums on how to present one's profile, new users provided a wealth of information about their job and occupation. In contrast, the "Tritagonist" profile gradually became a socially accepted front in the BOL forum, as seen in the steady increase in the proportion of profiles from this category. The emergence of this prominent front seemed related to the main front of another type of virtual environment, that of online chatting. The mostly blank profiles of "Tritagonists" reminded of participants in chat rooms who are usually only identified by their user id. An interpretation of this observation could be that, in order to present themselves in a new virtual environment, some people may get inspiration from established fronts in other virtual environments. New participants in the BOL forum who were familiar with online chats may have used familiarity with the fronts presented in online chats in order to present their profile in the BOL forum. Finally, over time, the "Deuteragonist" and the "Tritagonist" categories became the most prevailing ones. New users could get inspiration from existing profiles $^{3}$, which led to a self-perpetuating process. It is possible that the "Deuteragonist" and "Tritagonist" categories of profiles became prevalent through mimicry: new users could get inspiration for their profile from existing ones. Since most profiles were from the "Deuteragonist" or the "Tritagonist" category, new users could mimic these types of profiles. This mimetic behavior in turn could enact the emerging norms of what a profile in the BOL forum should be.

${ }^{3}$ Up until after data were collected (see supra, methods section), new users could freely browse the profiles of already registered users before registering. 


\section{Conclusion}

This research investigated how people present themselves in a virtual yet workrelated environment by providing a grounded analysis of 309 profiles of users of an occupational online forum.

This research is not without limitations. In particular, collected data were solely constituted by users' profiles, and no investigation was made of users' motivations. Moreover, profiles were collected, but not the interactions that actual took place in the BOL forum. Yet, electronically mediated interactions also affect impressions building in virtual environments. Future research should investigate the relationships between the presentation of self in virtual environments and the actual interactions that take place in them.

Despite these limitations, this research holds several noteworthy conceptual and managerial implications. In terms of theory, this research advances toward an understanding of behavior in virtual but work-related environments. The analysis revealed several distinct categories of participants that presented themselves in a strikingly different way in the online forum and thus seemed to pursue diverse impressions management strategies. As this research only investigated a banking online forum, no statistical generalization can be sought regarding the four categories that emerged from the samples. However, a conceptual generalization of these findings [42] could be that participants in a virtual environment tend to adopt one of several main types of profiles. Some of these fronts are likely to become dominant over time. This research also helped understand better how people build the relationship between their virtual and their "real" (or offline) self. It showed how people play with various degrees of mystification and how they may use offline social markers to establish their virtual self and impress their audience in different ways. Finally, this research discovered that, over time, how participants present themselves is related to the emergence of shared norms in a virtual environment.

With regard to practice, the temporal dimension of findings suggests that the design and management of online forums could change according to the stage of development of the online forums. New profiles could be monitored to encourage stronger involvement in the forums at different stages of their evolution.

\section{References}

1. L. Sproull and A.C. Kiesler, Connections. New ways of Working in the Networked Organization (MIT Press, 1991).

2. M. Castells, La société en réseaux - t. I: L'ère de l'information (Fayard, Paris, 1998).

3. S. R. Hiltz and M. Turoff, The Network Nation: Human Communication via Computer (Addison-Wesley, 1978).

4. P. Hinds and S. Kiesler, Communication Across Boundaries: Work, Structure and Use of Communication Technologies in a Large Organization, Organization Science 6(4), 373393 (1995). 
5. J.B. Walther, Computer-mediated Communication: Impersonal, Interpersonal and Hyperpersonal Interaction, Communication Research 23(1), 3-43 (1996).

6. S. Turkle, Life on the Screen. Identity in the Age of the Internet (Simon and Schuster, 1995).

7. N. Ellison, R. Heino, and J. Gibbs, Managing Impressions Online: Self-presentation Processes in the Online Dating Environment, Journal of Computer Mediated Communications 11(2), 2006.

8. H. Miller, The Presentation of Self in Electronic Life: Goffman on the Internet. Paper presented at the Embodied Knowledge and Virtual Space Conference, Goldsmiths' College, University of London, UK, 1995.

9. J. Cummings, L. Sproull, and S. Kiesler, Beyond Hearing: Where Real World and Online Support Meet, Group Dynamics: Theory, Research and Practice 6(1), 78-88 (2002).

10. R. Kling and C. Courtright, Group Behavior and Learning in Electronic Forums: A Socio-technical Approach, The Information Society 19(3), 221-235 (2003).

11. A. McLure Wasko and S. Faraj, Why Should I Share? Examining Social Capital and Knowledge Contribution in Electronic Networks of Practice. MIS Quarterly 29(1), 35-57 (2005).

12. D. Constant, L. Sproull and S. Kiesler, The Kindness of Strangers: The Usefulness of Electronic Weak Ties for Technical Advice. Organization Science 7(2),119-135(1996).

13. A. Kankanhalli, B.C.Y. Tan and K.K. Wei, Contributing Knowledge to Electronic Repositories: An Empirical Investigation, MIS Quarterly 29(1), (2005).

14. J. Preece, B. Nonnecke and D. Andrews, The Top Five Reasons for Lurking: Improving Community Experiences for Everyone, Computers in Human Behavior 20: 201-223 (2004).

15. B. Butler, L. Sproull, S. Kiesler, and R. Kraut, Community Effort in Online Groups: Who Does the Work and Why? in: Leadership at a Distance, edited by S. Weisband and L. Atwater (Erlbaum, 2004)

16. E. Goffman, The Presentation of Self in Everyday Life (Doubleday, Garden City, NY, 1959).

17. E. Goffman, The Interaction Order, American Sociological Review 48(1), 1 - 17

18. J. S. Donath, Identity and Deception in the Virtual Community, in: Communities in Cyberspace, edited by M. Smith and P. Pollock (Routledge, London, 1999).

19. R.A. Friedman and S.C. Currall, Does E-mail Escalate Conflict? MIT Sloan Management Review (44:1), 14-15 (2002).

20. J. Meyrowitz, No Sense of Place: The Impact of Electronic Media on Social Behavior (Oxford University Press, New York, 1985).

21. D. Waskul and M. Douglass, Cyberself: The Emergence of Self in Online-chat, The Information Society 13: 375- 397 (1997).

22. Z Papacharissi, The Blogger Revolution? Audiences as Media Producers, in: Blogging, Citizenship, and the Future of Media, edited by M. Tremayne (Routledge, New York, 2006).

23. K. Walker, "It's difficult to hide it": The Presentation of Self on Internet Home Pages, Qualitative Sociology 23(1), 99-120 (2000). 
24. S. J. Winter, C. Saunders, and P. Hart, Electronic Window Dressing: Impression Management with Websites, European Journal of Information Systems 12: 309-322 (2003).

25. J.R. Dominick, J. R., Who Do You Think You Are? Personal Home Pages and Selfpresentation on the World-Wide Web, Journalism and Mass Communication Quarterly 76(4), 646-658 (1999).

26. E.E. Jones, Interpersonal Perception (W. H. Freeman, New York, 1999).

27. H.J. Schau and M.C. Gilly, We Are What We Post? Self-presentation in Personal Web Space, Journal of Consumer Research 30(3), 385-404 (2003).

28. M. R. Leary, Self-Presentation: Impression Management and Interpersonal Behavior (Brown \& Benchmark Publishers, Madison, Wis.,1995).

29. M.S. Feldman, Strategies for Interpreting Qualitative Data (Sage, Thousand Oaks, CA, 1995).

30. M.B. Miles and A.M. Huberman, Qualitative Data Analysis - A Source Book of New Methods (DeBoeck Université, 1984).

31. M.C. Boudreau and D. Robey, Enacted Integrated Information Technology: A Human Agency Perspective, Organization Science 16(1), 3-18 (2005).

32. A.L. Strauss and J. Corbin, Basics of Aualitative Research - Techniques and Procedures for Developing Grounded Theory (Sage, London, 1988).

33. J. Beaty, P.J. Hunter, and C.E. Bain, (Eds.), The Norton Introduction to Literature (7th ed.) (W. W. Norton \& Company, New York, 1998).

34. R.C. Flickinger, The So-called Rule of Three Actors in the Classical Greek Drama, Classical Philology 6(2), 227-230 (1911).

35. S. Kluge, Empirically Grounded Construction of Types and Typologies in Qualitative Social Research, Forum: Qualitative Social Research (1:1) 2000.

36. F. Chaput Waksler, Erving Goffman's Sociology: An Introductory Essay, Human Studies 12(1-2), 1-18 (1989).

37. H.K. Klein and M.D. Myers, A Set of Principles for Conducting and Evaluating Interpretive Field Studies in Information Systems, MIS Quarterly 23(1), 67- 93 (1999).

38. A.S. Lee, Electronic Mail as a Medium for Rich Communication: An Empirical Investigation Using Hermeneutic Interpretation, MIS Quarterly 18(2), 143-157 (1994).

39. J. Westfall, What is Cyberwoman: The Second Sex in Cyberspace, Ethics and Information Technology 2(3), 159-166 (2000).

40. J.E. Dutton, J.M. Dukerich, and C.V. Harquail, Organizational Images and Member Identification, Administrative Science Quarterly 39: 239- 263 (1994).

41. J. Van Maanen and S.R. Barley, Occupational Communities: Culture and Control in Organizations, Research in Organizational Behavior 6: 287-365 (1984).

42. A. S. Lee and R.L. Baskerville, Generalizing Generalizability in Information Systems Research, Information Systems Research 14(3), 221-243 (2003).

\section{About the Author}

Emmanuelle Vaast is Assistant Professor of Management of Information Systems at the School of Business, Long Island University, in Brooklyn, NY. Her research interests deal with 
the practices and social representations related to the management and use of Information Systems within and across organizations and to the relationships between online and offline behaviors. Her research has appeared in MIS Quarterly, Organization Science, Journal of Management Information Systems, and Information and Organization, among others. Emmanuelle earned her $\mathrm{PhD}$ in Management of Information Systems from the Ecole Polytechnique, Paris, France. 